\title{
Sarcopenia and Bone Mass Loss as Risks during Aging on Female Elderly with Light Activity
}

\author{
Yoni Astuti ${ }^{1 *}$, Zulkhah Noor ${ }^{2}$, Rahmah Rahmah ${ }^{3}$ \\ ${ }^{1}$ Department of Biochemistry, Faculty of Medicine and Health Sciences, Universitas Muhammadiyah Yogyakarta, Yogyakarta, \\ Indonesia; ${ }^{2}$ Department of Physiology, Faculty of Medicine and Health Sciences, Universitas Muhammadiyah Yogyakarta, \\ Yogyakarta, Indonesia; ${ }^{3}$ Department of Pediatrics Nursing of Nursing Schools, Faculty of Medicine and Health Sciences, \\ Universitas Muhammadiyah, Yogyakarta, Indonesia
}

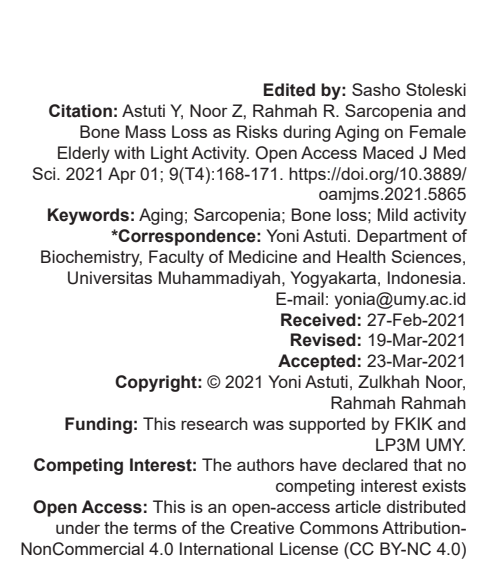

\begin{abstract}
BACKGROUND: Aging is a normal physiological process. The aspect of aging can be delayed by a measurable activity that is carried out early and regularly also intake health nutrition. Measurement of body composition is needed to analyze physiological changes due to aging so it can be used to compile a program of activities also diet to delay the aging process.

AIM: The aim of this study is to address the potential risks during aging process in people with light physical activity in Gamping, Patukan.

METHODS: Method of this research is the cross-sectional method. Subjects were 190 females with light physical activity that divided into Group 1 ( 70 females) with an average age $43.71 \pm 5.37$ years old and Group 2 (120 females) with an average age $61.72 \pm 6.82$ years old. Body composition was measured by the whole body composition diagnostic scale BG21.

RESULTS: The result showed that t-test between Group 1 and Group 2 was significant differences $p<0.05$, $\mathrm{Cl}=0.95$ in weight body, body mass index (BMI), muscle mass, bone mass, and active metabolism rate (AMR). The percentage decreasing number for body composition was $13.5 \%, 12.5 \%, 8.9 \%, 4.2 \%, 25.9 \%$, and $12.8 \%$ on weight, $\mathrm{BMI}$, muscle mass, bone mass, and AMR, respectively.

CONCLUSION: Female with light activity has a risk as sarcopenia and bone loss during aging. The future programme of this community need to encourage of increasing the physic activity and improving life style to slow the bone loss
\end{abstract} and muscle loss.

\section{Introduction}

Aging is a normal physiological process. The aspect of aging can be delayed by a measurable activity that is carried out early and regularly also intake health nutrition [1], [2], [3]. The reduction in physiological conditions will have an impact on the physical fitness of the elderly [3], [4]. Elderly aged> 60 years who can maintain good physical fitness will inhibit the degenerative process. However, the facts found in the community are that there are still many elderly people who experience physical decline due to not maintaining physical fitness [4], [5]. It is predicted the number of elderly people in 2020 (27.08 million), in 2025 (33.69 million), in 2030 (40.95 million), and in 2035 (48.19 million) and will continue to increase [6]. Indonesia has three provinces with the largest percentage of elderly people, namely, Yogyakarta (13.81\%), Central Java (12.59\%), and East Java (12.25\%) [5]. Most of old female in Yogyakarta is living with their family so that they have daily activities such as sweeping the floor or yard, playing with their grandchildren, and chatting with their neighbor [6]. Light-intensity activities include domestic or occupational tasks such as washing dishes, hanging washing, ironing, cooking, eating, working at a computer desk, or performing other office duties [7], [8]. Light-intensity activity is an activity that has a metabolic equivalent of $1.6<3.0$ METs or a relative intensity of $40<55 \%$ HRmax. Activity is shown to be a major determinant of total daily energy expenditure. Other studies have revealed an association between energy expended in non-exercise activities such as intensity of activities in the home, garden and work tasks, and risk of obesity, and with other risk factors such as glucose control [8]. Body composition changes from day to day due to health status. Many studies have shown that good physical activity can increase the degree of health which affects body composition [9]. Physical activity is one of the factors that can prevent the spread of non-communicable diseases such as cardiovascular disease, stroke, diabetes, and several types of cancer and physical activities which have also been shown to correlate with improved mental health, slow the onset of dementia, and improve quality of life also welfare. Research on the health benefits of physical activities is widely reported and is well documented positive with higher rates and higher frequency of physical activities associated with reduced risk and improved health in a number of key areas [10]. It is important to assess 
body composition to predict potential risk factors in the elderly with light activity.

\section{Methods}

Subjects were 190 females with mild physical activity based on questionnaire that divided into Group 1 (70 females) with an average age $43.71 \pm 5.37$ years old and Group 2 (120 females) with an average age $61.72 \pm 6.82$ years old. Body composition measurement using whole body composition diagnostic scale BG21 series from Beurer Germany. The scale is working based on bioelectric impedance analysis, which is predict body fat $(\%)$, body fluid $(\%)$, basal metabolic rate (BMR), body mass index (BMI), muscle mass (\%), bone mass $(\%)$, and active metabolism rate (AMR). Blood glucose detected by easy touch equipment, systole and diastole also heart rate detect by TensiOne OneMed.

This research has number for ethical clearance issued by KEPK UMY, No.014/EC-EXEM-KEPK FKIK UMY/I/2020.

\section{Results}

Body composition of the subject is shown in Table 1 for Group 1 (age <50 years old).

Table 1: Characteristic and body composition Group $1(n=70)$

\begin{tabular}{lllll}
\hline Type of measurement & Average & No. & Type of measurement & Average \\
\hline Age (years) & $43.71 \pm 5.37$ & 8 & Muscle mass $(\%)$ & $31.31 \pm 1.45$ \\
Height $(\mathrm{cm})$ & $154.53 \pm 5.60$ & 9 & Bone mass $(\%)$ & $65.24 \pm 1.35$ \\
Weight $(\mathrm{kg})$ & $65.12 \pm 9.79$ & 10 & AMR $(\%)$ & $18.43 \pm 1.43$ \\
Body fat $(\%)$ & $35.47 \pm 3.84$ & 11 & Systole $(\mathrm{mmHg})$ & $139.12 \pm 3.27$ \\
Body fluid $(\%)$ & $46.72 \pm 3.27$ & 12 & Diastole $(\mathrm{mmHg})$ & $87.76 \pm 1.46$ \\
BMR $($ Calorie) & $1353.24 \pm 1.01$ & 13 & Heart rate $(\mathrm{per}$ minute) & $85.65 \pm 9.73$ \\
BMI $\left(\mathrm{kg} / \mathrm{m}^{2}\right)$ & $26.84 \pm 3.31$ & 14 & Glucose $(\mathrm{mg} / \mathrm{dL})$ & $112.41 \pm 4.16$ \\
\hline BMl: Body mass index, AMR: Active metabolism rate, BMR: Basal metabolic rate.
\end{tabular}

Body composition of the subject in Group 2 (age $>50$ years old) is shown in Table 2 .

Table 2: Characteristic and body composition of Group $2(n=120)$

\begin{tabular}{|c|c|c|c|c|}
\hline Type of measurement & Average & No. & Type of measurement & Average \\
\hline Age (years) & $61.72 \pm 6.82$ & 8 & Muscle mass (\%) & $30.00 \pm 5.52$ \\
\hline Height $(\mathrm{cm})$ & $152.19 \pm 5.83$ & 9 & Bone mass (\%) & $48.36 \pm 1.17$ \\
\hline Weight (kg) & $56.32 \pm 1.09$ & 10 & $\operatorname{AMR}(\%)$ & $16.08 \pm 1.85$ \\
\hline Body fat (\%) & $35.67 \pm 4.05$ & 11 & Systole (mmHg) & $148.39 \pm 2.57$ \\
\hline Body fluid (\%) & $45.94 \pm 5.31$ & 12 & Diastole (mmHg) & $83.78 \pm 9.36$ \\
\hline BMR (Calorie) & $1183.56 \pm 1.26$ & 13 & Heart rate (beat/minute) & $85.31 \pm 1.07$ \\
\hline BMI (kg/M) & $24.44 \pm 5.07$ & 14 & Glucose $(\mathrm{mg} / \mathrm{d})$ & $137.17 \pm 7.81$ \\
\hline
\end{tabular}
composition is shown in Table 3 . The bone mass has the highest decreasing percentage around 25.9, meanwhile, muscle mass decreases around $4.9 \%$.

Figure 1 shows that body composition between Group 1 and Group 2 has different significant on weight $(\mathrm{kg})$, BMl $\left(\mathrm{kg} / \mathrm{m}^{2}\right)$, muscle mass, bone mass, and AMR.
Table 3: The decreasing percentage number of body composition

\begin{tabular}{ll}
\hline Body composition & Decreasing percentage number \\
\hline Weight $(\mathrm{Kg})$ & 13.5 \\
BMR $($ Calorie) & 12.5 \\
BMI $\left(\mathrm{kg} / \mathrm{m}^{2}\right)$ & 8.9 \\
Muscle mass $(\%)$ & 4.2 \\
Bone mass $(\%)$ & 25.9 \\
AMR $(\%)$ & 12.8 \\
\hline
\end{tabular}

As shown in Table 4, there was still normal value on body fat, body fluid, heartbeat, and blood glucose level both in Groups 1 and 2.

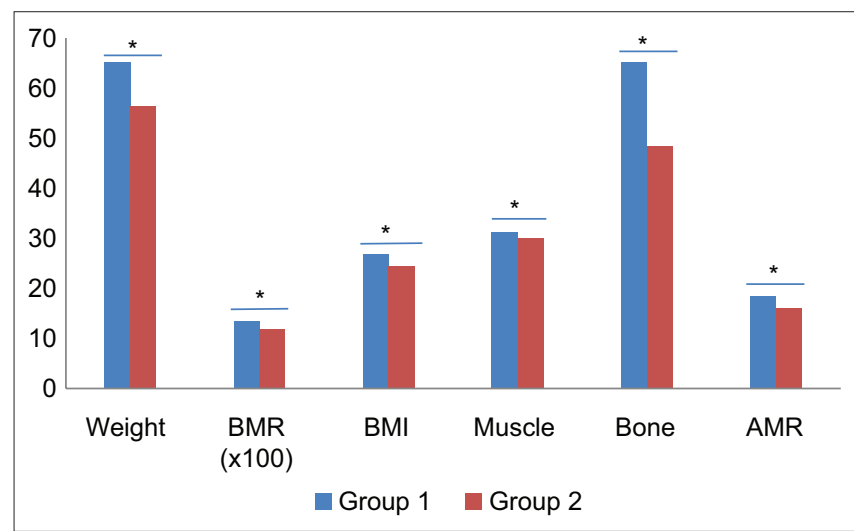

Figure 1: The t-test of weight $(\mathrm{kg})$, body mass index $\left(\mathrm{kg} / \mathrm{m}^{2}\right)$, muscle mass (\%), bone mass (\%), and active metabolism rate between Group 1 and Group 2. $p<0.05$, significant difference (*), $\mathrm{Cl}=0.95$

Systole and diastole were high since the aging process of the endothelium composition.

Table 4: The insignificant different of body composition ( $p>0.05$, $\mathrm{Cl}=0.95)$ between Group 1 and Group 2

\begin{tabular}{llll}
\hline Type of measurement & \multicolumn{2}{l}{ Group } & p-value \\
\cline { 2 - 3 } & 1 & 2 & \\
\hline Height $(\mathrm{cm})$ & $154.53 \pm 5.60$ & $152.19 \pm 5.83$ & 0.194 \\
Body fat $(\%)$ & $35.47 \pm 3.84$ & $35.67 \pm 4.05$ & 0.886 \\
Body fluid $(\%)$ & $46.72 \pm 3.27$ & $45.94 \pm 5.31$ & 0.939 \\
Systole $(\mathrm{mmHg})$ & $139.12 \pm 3.27$ & $148.39 \pm 2.57$ & 0.215 \\
Diastole $(\mathrm{mmHg})$ & $87.76 \pm 1.46$ & $83.78 \pm 9.36$ & 0.457 \\
Heart rate $(\mathrm{beat} /$ minute $)$ & $85.65 \pm 9.73$ & $85.31 \pm 1.07$ & 0.970 \\
Glucose $(\mathrm{mg} / \mathrm{dL})$ & $112.41 \pm 4.16$ & $137.17 \pm 7.81$ & 0.360 \\
\hline
\end{tabular}

\section{Discussion}

The degenerative process during aging is common in human, but to delay or to slow the aging is possible to apply. In this research we found the difference of body composition in group 1 and group 2. Based on manual of the BIA (bioelectric impedansi analyze) that the use to measure body composition, in group 1 shows that body fat (\%) was bad (because the value $>30,1$ ), body fluid (\%) was good (because in range 45-65 \%), BMR (Basal Metabolic Rate) that reflect the total energy for rest to maintain basic function was normal, BMI (Body Mass Index) that reflect a value to evaluate body weight due to find the categories of body weight was overweight or obesity (because in range 25-40), Muscle Mass (\%) was normal (because in range 31-36 \%), Bone Mass (\%) that reflect as total weight of bone (contain of organic substances, an anorganic subtances also water) was normal and AMR (Active Metabolism Rate) was normal. 
Meanwhile the categories of average value in group 2, based on manual of the BIA for body fat (\%) was bad ( because the value $>31,1$ ), body fluid (\%) was good (because in range 45-65 \%), BMR (Basal Metabolic Rate) was total energy for rest to maintain basic function was normal, BMI (Body Mass Index) that reflect a value to evaluate body weight due to find the categories of body weight was normal ( because in range 25,040,0 ), Muscle Mass (\%) was normal (because in range 28-34 \%), Bone Mass (\%) that reflect as total weight of bone (organic substances, an anorganic subtances also water) was normal and AMR (Active Metabolism Rate) were normal. The average of BMI also Body weight in both of group tend to reduce probably due to reduce of bone mass also muscle mass. Bone mass reducing was higher than muscle mass. As we know aging in female was associated with decrasing of estrogen hormone level [4], [5]. The bone development occurs since toddlers and maximum in age around 30-40 [4], [5]. Reducing bone mass slowly occurs during more than 40 years old so that able to impact on osteoporosis risk. This result in line with reporting that a significant relationship between osteoporosis and loss of muscle mass on elderly in Japan [11], [12]. There were interaction between bone and muscle as endocrine organ. Bone produce some secreted subtances referred to as myokines. Many myokines have a role to bone repair and bone metabolism such as adenosine triphosphate, Dickkopf-1, dentin matrix acidic phosphoprotein 1, nitric oxide, osteoprotegerin, RANKL, gamma-carboxyglutamic acid-containing protein, osteocalcin, prostaglandins, sclerostin. Muscle also influence the bone by brainderived neurotrophic factor, chemokine (C-X-C motif) Ligand 1, interleukins, leukemia inhibitory factor and TGF $\beta 1$ [13]. Estrogen may have a direct effect in muscle mass, because of the cell membrane skeletal muscle contains beta estrogen receptors.

Mechanism of estrogen reduction may have a negative effect on muscle mass although the mechanism is not well understood. However, it may be related to an increase in pro-inflammatory cytokines such as tumor necrosis factor- $\alpha$ and IL-6, which to be implicated mechanism of sarcopenia [14]. The bone-muscle unit influenced by some factors such as sex, nutrition, weight, age, and physical activity [15], [16]. Osteosarcopenia induced by low physical activity and inadequate nutrition [17]. Physical fitness has an important effect on bone density in postmenopausal women even though relatively small significant. Exercise is able to affect bone mass density, for example, is done with the neck of the femur. This exercise is a progressive resistance strength exercise for the lower leg [18]. Postmenopausal women have shown that physical activity can slow the rate of bone loss in weight-bearing areas of the body with an effect of about $1 \% / y e a r$. This has been proven strongly in research on the effect of daily walking on femoral cervical mass in postmenopausal women [19]. Exercise can be considered as a physical activity a promising therapeutic strategy for inhibiting the loss of bone and muscle mass due to osteosarcopenia. The type of exercise that can stimulate osteogenic effects to increase bone mass, bone tissue, namely exercise that have a mechanical load that exceeds daily activities such as Resistance Exercise (RE). RE stimulates MPS by activating the PI3K-AktmTORC1 signal, thus applying a mechanical load to the bone causes increased bone strength [20], [21].

\section{Conclusion}

This research found that female during aging with light activity has a risk to loss the muscle mass also the bone mass. The next program for female elderly should increase the physical activity.

\section{References}

1. Ying J, Ying Z, Mengmeng J, Zhaoyan G, Yu P, Ping M Aged-related changes in body composition and association between body composition with bone mass density by body mass index in Chinese han men over 50-year-old. PLoS One. 2015;10(6):e0130400. https://doi.org/10.1371/journal. pone. 0130400

PMid:26090818

2. Fornelli G, Isaia GC, D'Amelio P. Review ageing, muscle and bone. Geriatr Bone Unit JGG. 2016;64:85-90.

3. Amelia GG, Teresa F, Borja G, Jose AL. Exercise and bone mass in adults. Sports Med. 2009;39(6):439-68.

PMid:19453205

4. Pegah JN, Julia EI, Wendimere R, Owen JK, Jasminka ZI Aging human body: Changes in bone, muscle and body fat with consequent changes in nutrient intake. J Endocrinol. 2019;234(1):37-51.

PMid:28442508

5. Robin MD, David WD, Neville OD, Jonathan ES, Paul Z. Does high-intensity resistance training maintain bone mass during moderate weight loss in older overweight adults with Type 2 diabetes? Osteoporos Int. 2005;16(12):1703-12. https://doi. org/10.1007/s00198-005-1906-4

PMid:15937634

6. Irene RG, Asier M, Jose LR, Leocadio RG, Sebastien FM, Luis MA, et al. Associations between sedentary time, physical activity and bone health among older people using compositional data analysis. PLoS One. 2018;13(10):e0206013. https://doi. org/10.1371/journal.pone. 0206013

PMid:30346973

7. Gaib H, Sugeng S. Profile of Indonesian Women. Jakarta: Ministry of Women's Empowerment and Child Protection; 2018.

8. Kevin N, Lynda N, Daryl S. Review Position statement on physical activity and exercise intensity terminology. J Sci Med Sport. 2010;13(5):496-502.

PMid:20005170

9. Joseph LJ, Trappe TA, Farrell PA, Campbell WW, Yarasheski KE, Lambert CP, et al. Short-term moderate weight loss and resistance training do not affect insulin-stimulated glucose disposal in postmenopausal women. Diabetes Care. 
2001;24(11):1863-9. https://doi.org/10.2337/diacare.24.11.1863 PMid:11679448

10. Jan $C$, Veronika $T$, Milan $S$, Helmut $K$, Winfried $M$, Dušan $H$. Physical activity in elderly. Eur J TransI Myol. 2015;25(4):249-52. PMid:26913164

11. Nuria RE, Nancy B, Andres DL, Dora RJ, Alfredo M, Vicente MS, et al. Leisure-time physical activity at moderate and high intensity is associated with parameters of body composition, muscle strength and sarcopenia in aged adults with obesity and metabolic syndrome from Q5 the PREDIMED-Plus study. Clin Nutr. 2018;38(3):1324-31. https://doi.org/10.1016/j. clnu.2018.05.023

PMid:29910068

12. Yoshiaki T, Hyuma M, Ryoji K, Kazutoshi T, Yuki N, Takuro K, et al. The association between osteoporosis and grip strength and skeletal muscle mass in community-dwelling older women. Int J Environ Res. 2019;16(7):1228. PMid:30959864

13. Battafarano G, Rossi M, Marampon F, Minisola S, Del Fattore A. Bone control of muscle function: Review. Int $\mathrm{J} \mathrm{Mol} \mathrm{Sci.}$ 2020;21(4):1178. https://doi.org/10.3390/ijms21041178 PMid:32053970

14. Colón CJ, Vicenty IL, Rodríguez MF, Ferré AG, Rivera BP,Vélez GC, et al. Muscle and bone mass loss in the elderly population: Advances in diagnosis and treatment. $\mathrm{J}$ Biomed. 2018;3:40-9. https://doi.org/10.7150/jbm.23390 PMid:30505650
15. Arazi HH, Eghbali E. Effects of different types of physical training on bone mineral density in men and women. J Osteop Phys Activity. 2017;5:3. https://doi.org/10.4172/2329-9509.1000207

16. Mosavata M, Mirsanjarib M, Omara SZ, Sadeghi H. Review paper: Bone health, exercise and nutrition. J Adv Appl Sci. 2014;2:143-56.

17. Belchior GF, Kirk B, da Silva EA, Duque G. Osteosarcopenia: Beyond age-related muscle and bone loss. Eur Geriatr Med. 2020;11(5):715-24. https://doi.org/10.1007/ s41999-020-00355-6

PMid:32676865

18. Sandra Z, Simone M, Stefan L, Hannah F, Samantha B, Ján C et al. Physical exercise in aging: Nine weeks of leg press or electrical stimulation training in 70 years old sedentary elderly people. Eur J Transl Myol. 2015;25(4):237-42. https://doi. org/10.4081/ejtm.2015.5374

PMid:26913162

19. Benedetti MGk, Furlini G, Zati A, Mauro GL. Review article: The effectiveness of physical exercise on bone density in osteoporotic patients. Biomed Res Int 2018;2018:4840531. https://doi.org/10.1155/2018/4840531

20. Hong AR, Kim SW. Review article: Effects of resistance exercise on bone health. Endocrinol Metab. 2018;33(4):435-44 PMid:30513557

21. Curtis E, Litwic A, Cooper C, Dennison E. Determinants of muscle and bone aging. J Cell Physiol. 2015;230(11):2618-25. https://doi.org/10.1002/jcp.25001

PMid:25820482 